\author{
ARTIGO \\ do https://doi.org/10.22481/praxisedu.v16i39.5129
}

\title{
CRENÇAS DE PROFESSORES SOBRE AS HABILIDADES NO CONTEXTO ESCOLAR E A TEORIA HISTÓRICO CULTURAL
}

\author{
TEACHER'S BELIEFS ABOUT ABILITIES IN THE SCHOOL CONTEXT AND \\ HISTORICAL CULTURAL THEORY
}

\begin{abstract}
CREENCIAS DE PROFESORES SOBRE LAS HABILIDADES EN EL CONTEXTO ESCOLAR E TEORIA HISTÓRICA CULTURAL
\end{abstract}

Isauro Beltrán Núñez

Universidade Federal do Rio Grande do Norte - Brasil

Magda Maria Pinheiro de Melo

Universidade Federal do Rio Grande do Norte - Brasil

\begin{abstract}
Resumo: A categoria "habilidade", assim como "competência", tem relevância na organização e no desenvolvimento do currículo na educação básica, por isso o interesse em estudar o pensamento docente sobre o que são habilidades e sua formação. Este artigo apresenta os resultados de uma pesquisa de natureza exploratória que identificou e caracterizou crenças de professores da educação básica de escolas públicas sobre as habilidades e a sua formação, no contexto escolar, considerando o papel desse tipo de conhecimento para a atividade profissional da docência. A pesquisa teve como referência as contribuições da teoria Histórico-Cultural de L. S. Vigotsky e alguns de seus seguidores. Como instrumento de coleta de dados foi usado um questionário normativo, de escala tipo Likert, convenientemente elaborado e validado pelos pesquisadores. Entre os resultados mais importantes, verifica-se que, no modelo de crenças dos professores, existe um hiato no que diz respeito à matriz teórica de referência, destacando-se, em especial, o entendimento das habilidades como tipo de atividade que implica o domínio não consciente de sua estrutural operacional orientada à aplicação de conhecimentos, assim como o de que as habilidades apresentam a mesma estrutura das competências. Esse conhecimento das crenças dos professores sobre o referido domínio da atividade profissional é um elemento chave que deve ser levado em conta nos programas de formação e de desenvolvimento profissional dos docentes.
\end{abstract}

Palavras-chave: Crenças; Enfoque histórico-cultural; Habilidades.

Abstract: The category "ability", as well as "competence", has relevance in the organization and development of the curriculum in basic education, so the interest of studying the teachers' thinking about what are abilities and their training. This article presents the results of an exploratory research that identified and characterized the beliefs of teachers in basic public school education about the abilities and their training in the school context, considering the role of this type of knowledge for the professional activity of teaching. The research had as reference the contributions of the Historical- 
Cultural theory of L. S. Vygotsky and some of its followers. For data collection instrument, the researchers conveniently prepared, validated and used a normative, Likert-type questionnaire. Among the most important results, it appears that, in the teachers' belief model, there is a gap with regard to the theoretical reference matrix, especially in the understanding of abilities as the type of activity that implies the non-conscious domain of its operational structure oriented to the application of knowledge, as well as that the abilities have the same structure as the competences. This knowledge of teachers' beliefs about the aforementioned field of professional activity is a key element that must be taken into account in teacher training and professional development programs.

Keywords: Beliefs; Historical-cultural approach; Abilities.

Resumen: La categoría "habilidad", así como "competencia", tiene relevancia en la organización y el desarrollo del currículo en la educación básica, por eso el interés de estudiar el pensamiento docente sobre lo que son habilidades y su formación. Este artículo presenta los resultados de una investigación de naturaleza exploratoria, que identificó y caracterizó creencias de profesores de la educación básica de escuelas públicas sobre las habilidades y su formación en el contexto escolar, considerando el papel de ese tipo de conocimiento para la actividad profesional de la docencia. La investigación tuvo como referencia las contribuciones de la Teoría Histórico-Cultural de L. S. Vigotsky y algunos de sus seguidores. Como instrumento de recolección de datos se utilizó un cuestionario normativo, de escala tipo Likert, convenientemente elaborado y validado por los investigadores. Entre los resultados más importantes, parece que, en el modelo de creencias de los docentes, hay un hiato con respecto a la matriz de referencia teórica, destacándose, en especial, el entendimiento de las habilidades como tipo de actividad que implica en el dominio no consciente de su estructura operacional e orientada a la aplicación de conocimientos, así como que las habilidades tienen la misma estructura que las competencias. Este conocimiento de las creencias de los profesores sobre el referido dominio de la actividad profesional es un elemento clave que debe tenerse en cuenta en los programas de formación y de desarrollo profesional de los docentes.

Palabras clave: Creencias; Teoria histórico cultural; Habilidades.

\section{Introdução}

No Brasil, os movimentos das reformas educacionais que se têm operado, a partir dos anos de 1990, apoiam-se em novos discursos e propõem mudanças essenciais no que diz respeito às concepções de ensino e de aprendizagem. Essas mudanças, que acompanham as tendências mundiais do currículo escolar, incorporaram as competências básicas e as habilidades como elementos chave. Assim, como reflexo dessa realidade, constatamos a produção de referenciais curriculares nacionais, como os Parâmetros Curriculares Nacionais (PCN), as Diretrizes Curriculares Nacionais Gerais para a Educação Básica, e de sistemas de avaliação nacionais, tais como o Sistema de Avaliação da Educação Básica (Saeb), o Exame Nacional de Ensino Médio (ENEM) e o Exame Nacional para Certificação de Competências de Jovens e Adultos (ENCEJA), além da Base Nacional Comum Curricular (BNCC), estruturados 
a partir de competências e habilidades, evidenciando a importância que as reformas atribuem a essas categorias no currículo escolar.

Pérez (2007), ao analisar o ensino tradicional, verifica que, por vezes, este tem se configurado como o treinamento de habilidades, uma prática comum nas escolas, baseada na perspectiva condutista de aprendizagem. Para ele, essa perspectiva de ensino tem privilegiado o desenvolvimento e o treinamento de habilidades e capacidades formais, sem um vínculo adequado das habilidades com os conteúdos e com o contexto cultural em que essas habilidades adquirem significados.

Durante muitos anos, o conteúdo escolar tem sido compreendido como um conhecimento verbal, pronto para ser transmitido pelo professor e apenas recuperado pelos estudantes. Como explicam Pozo e Gómez Crespo (2009), muitos professores estão convencidos de que as dificuldades do não "saber fazer" são consequências da incapacidade de aplicar o que se sabe "falar", ou seja, de se separar os conteúdos conceituais dos procedimentais. Sendo assim, a teoria deve preceder sempre a prática, o que seria a aplicação do que foi previamente estudado. Essa concepção revela a ideia básica de que as pessoas dispõem de duas formas diferentes, e nem sempre relacionadas, de conhecer o mundo.

Zabala e Arnau (2010) chamam a atenção para o fato da impossibilidade de ocorrer uma aprendizagem relevante sem as habilidades, com as quais se constrói e se aplica o conhecimento conceitual. Dessa forma, as habilidades como conteúdos procedimentais na aprendizagem não só constituem técnicas e estratégias educativas de importância como também são um meio principal para a atividade mental dos alunos na compreensão dos conteúdos conceituais, imprescindíveis para explicar o mundo em que vivemos e os fenômenos que nele têm lugar.

O conteúdo conceitual não pode apenas representar o contexto de aplicação das teorias, do fazer da escola que separa os procedimentos de seu uso, como criticam Davidov e Slobodchikov (1991, p. 54). Esses autores explicam que, de acordo com a lógica dialética:

\footnotetext{
A realidade do conhecimento não está fechada nas abstrações verbais, mas sim nos procedimentos da atividade do sujeito cognoscente para quem a transformação dos objetos, a fixação dos meios para realizar essas transformações constituem componentes tão indispensáveis do 'conhecimento' como sua expressão verbal.
}

A problemática que diz respeito à formação de habilidade também é apontada por Talízina (2009). Para a autora, a escola dita tradicional tem prestado pouca atenção ao aspecto operacional da psique, preocupando-se mais com o formalismo do conteúdo dos conceitos. Em sua perspectiva, a formação de um conceito implica não só a formação de uma imagem especial 
como também de um sistema operacional que tenha uma estrutura interna determinada, e, dessa forma, o aspecto operacional constitui propriamente o mecanismo psicológico dos conceitos.

A Teoria da Atividade de Leontiev possibilita uma compreensão diferente da escola tradicional quanto à correlação entre conhecimentos e habilidades. O conhecimento não se opõe à habilidade, mas é parte de seu conteúdo na unidade dialética entre conceito e ação, como expresso na psicologia Histórico-Cultural. Assim, os conhecimentos constituem uma condição necessária para a formação e o desenvolvimento das habilidades. Ter domínio do conhecimento significa a capacidade de mobilizá-lo, usá-lo de forma produtiva e criativa, associada a procedimentos da atividade, que é dirigida a objetivos e impulsionada por motivos, necessidades e desejos.

Uma das dificuldades que muitos professores apresentam na formação de habilidades diz respeito à falta de conhecimento sobre a estrutura procedimental, ou seja, sobre o conjunto de operações que configuram a habilidade (NÚÑEZ, 2018; NÚÑEZ; RAMALHO, 2012; TALÍZINA, 2009), e, assim, geralmente transmitem (treinam) de forma "mecânica" o saber fazer. Essa limitação não contribui com o ensino de procedimentos pela via de sua compreensão, nem com a organização de um processo de ensino e de aprendizagem mais adequado à natureza das habilidades, etapas consideradas em um tipo de atividade que exige a consciência de seu sistema de operações. Quando se alcança essa consciência, é possível superar práticas espontâneas e de pouca contribuição para o desenvolvimento do pensamento estratégico dos estudantes.

Estudar e compreender as crenças ou os sistemas de crenças dos professores sobre as habilidades e sua formação no contexto escolar constitui uma preocupação de pesquisadores no campo da formação de professores. O estudo das crenças dos professores faz parte do processo de compreensão sobre como eles pensam e conceitualizam suas práticas de ensino. Marcelo e Vaillant (2009) argumentam que esses estudos devem ser um dos focos da pesquisa educacional, uma vez que podem contribuir para ampliar a compreensão sobre a prática educativa, servindo de referência para a concepção e o desenvolvimento de programas de formação. As crenças, como elemento do conhecimento profissional de professores sobre as habilidades e sua formação no currículo escolar, revelam-se como um objeto de estudo importante para a reflexão crítica das práticas e da formação docente.

Nesse contexto, este estudo se propõe a identificar e caracterizar as crenças que professores da educação básica têm sobre habilidades e sua formação no contexto escolar como parte do conhecimento profissional em relação ao marco da Teoria Histórico-Cultural (THC) 
de L. S. Vigotsky e alguns de seus seguidores, a fim de dispor de informações que possam contribuir com a formação continuada dos professores.

Para esse propósito, foram definidos os seguintes objetivos específicos:

a) elaborar e validar um questionário para identificar as crenças dos professores sobre a habilidade e sua formação no contexto escolar;

b) identificar e caracterizar as crenças dos professores sobre habilidades e sua formação.

Embora exista um grande número de estudos sobre a crença de professores a respeito de diferentes domínios de sua atividade profissional, não foram encontradas, nos levantamentos iniciais realizados na literatura especializada, pesquisas que abordassem as crenças sobre habilidades e sua formação sob a perspectiva da THC, o que faz deste estudo uma possível contribuição para esse domínio da atividade profissional docente.

\section{As crenças docentes}

A relação do pensamento docente com a prática profissional se expressa em um conteúdo que pode possibilitar pensar as formas pelas quais os professores interpretam o currículo como um projeto cultural (MARCELO, 2012). Segundo Clark e Peterson (1997), o comportamento do professor é substancialmente influenciado - e, até mesmo, determinado pelos processos de seu pensamento. As construções simbólicas que o professor desenvolve sobre o ensino se apoiam nos princípios, nas crenças e nos conceitos por eles elaborados, embora não estejam evidenciados ou expressos, uma vez que podem se situar no plano da "nãoconsciência”. Dessa forma, conhecer o pensamento docente é necessário quando se deseja promover mudanças nas práticas profissionais.

Para Ramalho, Núñez e Gauthier (2004, p. 27):

As ideias, crenças e concepções que têm os professores sobre sua prática profissional definem um dado modelo de atuação profissional. Esse princípio é um importante ponto de partida para os estudos dos processos de reconstrução da identidade profissional, da prática e da formação.

As crenças, os conhecimentos e as representações dos professores sobre a aprendizagem e o ensino têm sido estudados a partir das perspectivas do pensamento do professor (MARCELO, 2012; CLARK; PERTESON, 1997; RODRIGO; RODRIGUEZ; MARRERO, 1993) e do conhecimento profissional docente (PORLÁN; RIVERO, 1997; TARDIF, 2002; PORLÁN; DEL POZO; TOSCANO, 2002). Esses estudos sugerem também que as concepções 
dos professores sobre a aprendizagem estão relacionadas a suas práticas e concepções sobre o ensino, seja como professor, seja na sua história de vida como estudante.

Nos estudos realizados por Ashton (2019), mostra-se a controvérsia a respeito do termo crença no âmbito da área da formação e da atividade docente, em parte pela confusão semântica com outros vocábulos usados cotidianamente, em parte pela polissemia evidenciada pelas diferentes perspectivas teóricas que o discutem. As crenças podem ser compreendidas como teorias ou sustentações que as pessoas constroem para adaptar-se ao contexto, interpretar e justificar fatos, dar explicações a situações e guiar seu comportamento (RODRIGO; RODRIGUEZ; MARRERO, 1993). São também componentes do conhecimento pouco elaborado e subjetivo, que não se fundamentam na racionalidade e sim, preferencialmente, nos sentimentos e nas experiências, o que as faz consistentes e duradouras no tempo (LINARES, 1991). As crenças, no geral, influenciam os pensamentos, as opiniões e as atitudes das pessoas.

No nível das crenças, os sujeitos utilizam suas teorias para interpretar situações, fazer inferências práticas, prever e planejar ações, e tomar decisões face a demandas cognitivas de caráter pragmático. Essas ações demandam teorias, presentes no nível implícito, nas quais os sujeitos se apoiam em pontos de vistas pessoais sobre a realidade, e que não exigem movimentos da consciência para a ação. Nesse sentido, diferenciamos o conhecimento da crença, embora as crenças possam ser consideradas como componentes do conhecimento profissional (MARCELO, 2012).

Para Pajares (1992), as crenças são "verdades pessoais" indiscutíveis, sustentadas por cada pessoa, derivadas da experiência ou da fantasia, que têm um forte componente avaliativo e afetivo, e que se manifestam nas declarações verbais ou em ações, no último caso, são as formas de justificá-las. Para o autor, as crenças são, no geral, instrumentos para definir as tarefas e selecionar as ferramentas cognitivas com as quais podem interpretar, planejar e tomar decisões e, dessa forma, são relevantes na definição do comportamento e na organização do conhecimento e da informação.

Linares (1991, p. 37) considera as crenças como componentes do conhecimento (conhecimento subjetivo), pouco elaborado, produzido no nível particular por cada indivíduo para explicar-se e justificar muitas das decisões e atuações pessoais e profissionais vividas. Dessa forma, as crenças não se fundamentam na racionalidade, mas sim, sobre os sentimentos, as experiências e a ausência de conhecimentos específicos sobre tema com o qual se relaciona, o que as faz serem muito consistentes e duradouras para cada indivíduo. As crenças não se 
limitam à racionalidade e permanecem veladas para o próprio sujeito, que, muitas vezes, não tem consciência delas.

Zabalza (1994, p. 31) explica que a "atuação dos professores é dirigida pelos seus pensamentos (juízos, crenças, teorias implícitas etc.)”. Para ele, a conduta do professor e seu pensamento se relacionam, mais do que por aspectos racionais, por uma "racionalidade limitada". Por isso, a importância de se revelarem as crenças para que sejam consideradas nos processos que contribuem com as mudanças na cultura, na identidade, na prática e na formação docentes.

As predisposições pessoais dos professores, suas crenças sobre o que é ensinar e aprender, constituem um fator muito relevante do "ser e agir como professor", e seu comportamento é influenciado pelas experiências de vida que o levaram a desenvolver determinadas crenças. Por isso, a importância da formação inicial e continuada e da própria cultura profissional que favorecem o questionamento crítico dos professores sobre suas crenças, a fim de pensarem práticas inovadoras.

Muitos dos estudos realizados sobre as crenças dos professores foram feitos no nível individual. As contradições da THC de Vigotsky e alguns de seus continuadores, como Leontiev (2001) e Engestron (2001), permitem conferir às crenças não apenas a dimensão do sujeito, como também sua origem social, como explica Barahona (2014).

Nessa teoria, as crenças têm uma origem social dada nos contextos cultural, profissional e social, e nas interações que os professores desenvolvem nesses contextos. As vivências nos contextos anteriormente referidos e as opiniões neles geradas fortalecem as concepções pessoais, que, por sua vez, traduzem-se em crenças que estão em processos de internalização. Como explica Vigotsky (1988), esses processos se iniciam no plano interpsicológico, social, nas interações com os outros, e passam ao plano intrapsicológico, como elemento ou ferramenta psicológica de processos intrapessoais. As crenças são, consequentemente, ferramentas psicológicas dinâmicas, complexas, mediadoras da formação e do desenvolvimento do pensamento docente que, por sua vez, influenciam os comportamentos dos professores em relação a suas decisões profissionais.

Ao analisar sob uma perspectiva dialética, Negueruela (2011) argumenta que as crenças são de natureza contraditória. Sendo assim, segundo a THC, a incompatibilidade entre crenças e ações reflete crenças em ações. Disso se depreende a importância de a formação confrontar as crenças com a prática, de revelar as contradições que possam constituir fontes para a 
reestruturação do pensamento docente e, por sua vez, de estimular a aprendizagem docente que tributa para o desenvolvimento profissional, como apontam Ramalho, Núñez e Gauthier (2004).

Marcelo (2012) argumenta que os estudos sobre crenças dos professores devem ser um dos focos da pesquisa educacional, uma vez que podem contribuir para informar sobre a prática educativa a ponto de serem referência para os programas de formação. Nesse sentido, é preciso uma revisão crítica das diferentes crenças docentes sobre sua atividade profissional. Pozo (2006), por sua vez, entende que, para melhorar e transformar a escola, faz-se necessária uma mudança nas crenças dos agentes implicados nessa instituição, em especial, nas dos professores.

\section{Metodologia da pesquisa}

Considerando a novidade sobre o domínio das crenças em estudo, optou-se por um estudo de natureza exploratória, no qual se combinam, de forma dialética, as dimensões qualitativas e quantitativas do objeto da pesquisa, de acordo com o proposto por Nocedo (2001).

A pesquisa foi realizada segundo as seguintes etapas:

- Elaboração de um questionário de crenças sobre as habilidades e sua formação sob a perspectiva da THC.

- Aplicação e tratamento estatístico para determinar os enunciados válidos e confiáveis.

- Estabelecimento e caracterização de um modelo de crenças a partir dos valores das médias e dos desvios padrão dos enunciados selecionados.

Como instrumento de coleta de dados, foi construído e validado um questionário de escala do tipo Likert. Esse tipo de instrumento é adequado a este estudo pela natureza implícita das crenças que são o objeto da pesquisa (RODRIGO; RODRIGUEZ; MARRERO, 1993). Esse tipo de questionário apresenta uma boa aceitação entre os pesquisadores pela sua objetividade e elevadas validez e confiabilidade quando corretamente elaborado.

O questionário é composto por uma lista de enunciados referentes ao domínio das crenças (as habilidades e sua formação no contexto escolar) e uma escala numérica que representa o nível de concordância ou discordância em relação aos enunciados. As respostas assinaladas na escala numérica permitiram inferir as crenças a partir dos valores que os professores atribuíram a cada enunciado do questionário. Esse modelo de medição das crenças é de natureza normativa, e, embora seja simples, pode apresentar uma alta confiabilidade (RICHARDSON, 1996). Na elaboração do questionário, foram consideradas as seguintes etapas: 
a) Definição das dimensões (subdomínios e suas características) das habilidades e sua formação: o objetivo da definição do domínio (o objeto das crenças) foi tematizar adequadamente o campo de estudo para se poder definir as principais características deste. Para elaborar os enunciados ou itens das crenças sobre as habilidades (correspondentes a cada subdomínio), foi realizada uma análise de conteúdo da literatura especializada na temática, sob o enfoque teórico que direciona a pesquisa. Foram analisadas as obras de Vigotsky (1988), Leontiev (1985), Galperin (2001), Talízina (2001), Petrovsky (1979), Danilov e Skatkin (1980), assim como outros mais recentes que têm contribuído com essa discussão, tais como Rodriguez e Bermúdez (1999), Núñez (2009) e Farinã (2005), ou seja, as análises são feitas sob esse quadro teórico. Esse procedimento foi realizado baseado nas etapas da Análise de Conteúdo, segundo as orientações de Bardin (2011), o que permitiu a categorização do conteúdo. Dessa análise, levantou-se um conjunto de categorias que, ao serem classificadas, definiram os subdomínios e suas características (a serem transformados em enunciados).

b) Elaboração dos enunciados ou itens. Os itens ou enunciados deviam:

- conter apenas um elemento que caracteriza um subdomínio, referente ao domínio da escala;

- ser redigidos de forma clara e sem ambiguidades para também evitar a possibilidade de um contaminar ou influenciar outro.

- apresentar a máxima amplitude do conteúdo do domínio em estudo (crenças sobre habilidades e sua formação);

- responder a critérios psicométricos, a fim de garantir a unidimensionalidade da medida, o que possibilita valores constantes do objeto estudado (confiabilidade e validez), e realização de análises e interpretações quantitativas.

c) Foram elaborados os enunciados que compõem os itens, um total de 24, cujas possíveis respostas foram: Totalmente em Desacordo (TD); Desacordo (D), Indeciso (I); Acordo (A) e Totalmente de Acordo (TA). A cada uma dessas qualidades se atribuem valores numéricos, conforme apresentado no Quadro 1. Essa escala permite inferir as qualidades gerais de cada enunciado em termos das médias e dos desvios padrões, a partir das respostas dos professores, ao selecionarem uma categoria a qual atribuem determinada concordância ou não, associadas às crenças em questão. 
Quadro 1 - Valores numéricos da escala

\begin{tabular}{|c|c|}
\hline QUALIDADE & VALOR NUMÉRICO \\
\hline Totalmente de Acordo & 5 \\
\hline Acordo & 4 \\
\hline Indeciso & 3 \\
\hline Desacordo & 2 \\
\hline Totalmente em Desacordo & 1 \\
\hline
\end{tabular}

Fonte: Autores (2019).

d) Os enunciados foram intercalados em relação aos subdomínios para evitar a tendência de algumas pessoas de responder afirmativamente independentemente do conteúdo.

e) Realização das análises estatísticas: essa etapa permitiu controlar o grau de validade e de confiabilidade (consistência interna) dos itens e da própria escala.

f) A validação do conteúdo: cuja finalidade foi avaliar a adequação dos itens, os quais foram analisados por dois especialistas na área do estudo.

g) A consistência interna: determinada pelo cálculo do coeficiente estatístico Alpha de Cronbach, selecionando, assim, os itens mais representativos.

Dessa forma, foi definida uma versão do questionário.

Os enunciados selecionados foram analisados segundo os valores da média e dos desvios padrão, para se estabelecer um modelo das crenças dos professores sobre o domínio em estudo.

\section{Análise dos resultados da pesquisa}

Os resultados da pesquisa são analisados no sentido de atender aos objetivos específicos e, assim, alcançar o objetivo geral. No primeiro momento, apresenta-se a caracterização socioprofissional dos professores. Essa caracterização revela elementos importantes sobre o contexto e os participantes do estudo e diz respeito à validade de contexto, como alerta Perez (2007). No segundo momento, mostram-se os resultados da elaboração e da validação do questionário e, a seguir, as crenças identificadas, o que possibilita tipificar o pensamento dos professores sobre esse domínio de sua atividade profissional.

\section{O contexto e os professores participantes no estudo}

O estudo foi realizado com 221 professores de escolas públicas do Ensino Médio, do estado do Rio Grande do Norte. Do total dos professores, $48 \%$ são do sexo feminino e 51,6\% 
do sexo masculino, a maioria tem menos de cinquenta e cinco anos $(89,6 \%)$, existindo uma proporção significativa entre trinta e cinco e quarenta e cinco anos $(53,7 \%)$. Em relação às áreas das disciplinas que lecionam, pode ser observada a presença de professores de todas as áreas de conhecimento: Linguagem, 35,7; Ciências Humanas, 24,6\%; Ciências Naturais, 24,0\%; Matemática, 13,7\%. Desses professores, 72,0\% tem formação a nível de especialização, 7,2\% de mestrado, $0,9 \%$ de doutorado.

Dos professores, 85,5\% reconhecem ter conhecimento das Orientações Curriculares e das Novas Diretrizes Curriculares para o Ensino Médio, e 14,5 \% manifestam não ter esse conhecimento. Por último, os professores responderam se o programa da disciplina que ministram se organizava em termos de habilidades. Para $68,5 \%$ dos professores, a resposta foi positiva e, para $31,5 \%$, foi negativa.

\section{Resultados da elaboração e da validação do questionário de crenças}

A elaboração do questionário normativo para identificar e caracterizar o objeto das crenças dos professores sobre as habilidades e sua formação foi necessária, uma vez que, como explicado anteriormente, não encontramos antecedentes sobre esse domínio em estudos que tratam de crenças de professores. A revisão da literatura especializada e a análise de conteúdo dos textos em questão possibilitaram tematizar e definir, para o domínio em estudo (as habilidades e sua formação), três subdomínios: um conceitual (o que são habilidades), um operacional (qual é a estrutura de uma habilidade) e um formativo (como se formam e se desenvolvem as habilidades). Foram definidos, inicialmente, 31 enunciados distribuídos nos três subdomínios, segundo os critérios definidos na metodologia, e considerando a maior amplitude das características do domínio em estudo. Esses enunciados formaram parte da primeira versão do questionário.

Para a validação de conteúdo, o questionário foi submetido à apreciação de dois especialistas na temática do domínio das crenças em estudo, e foi avaliada a capacidade de os enunciados serem adequados aos subdomínios definidos. Em relação à validação do construto, os especialistas opinaram sobre a adequação dos enunciados ao marco teórico, nesse caso a Teoria Histórico-Cultural. Como resultado da análise dos especialistas, foi necessário modificar alguns aspectos da redação, da expressão e do conteúdo de alguns itens. Os resultados das respostas da aplicação do questionário permitiram a análise da consistência interna como medida da confiabilidade. 
A consistência se refere ao nível em que os diferentes enunciados da escala estão relacionados entre si. Essa homogeneidade entre os itens indica o grau de concordância entre eles e, consequentemente, determina que eles possam se acumular e dar uma resposta global. Na pesquisa, para esses propósitos, foi usado o coeficiente Alfa de Cronbach. Esse indicador foi escolhido porque seria feita apenas uma aplicação do questionário, o qual tem, para cada enunciado, mais de uma possibilidade de resposta, e a pontuação seria interpretada de forma global, o que é coerente com o estabelecido por Cronbach (1951). Quando o resultado do coeficiente é menor de 0,5 , o instrumento mostra uma baixa confiabilidade; se está entre 0,5 e 0,6, é ainda baixo; entre 0,6 e 0,7 é fraco; entre 0,7 e 0,8 é aceitável; entre 0,8 e 0,9 pode ser considerado bom; e, se superior a 0,9 , é excelente.

O Alpha de Cronbach foi de 0,9077, ou seja, um valor alto, o que indica uma elevada consistência interna. Em seguida, foram eliminados os enunciados que apresentavam uma correlação interna negativa ou menor que 0,5 .

Foram selecionados 24 enunciados, distribuídos segundo os subdomínios apresentados no Quadro 2. O número de enunciados contempla todos os fatores do domínio em estudo, pelo qual contribui com a validez do questionário.

Quadro 2 - Quantidade de item por subdomínio

\begin{tabular}{|c|c|c|}
\hline SUBDOMÍNIO & $\mathbf{N}^{\mathbf{0}}$ DE ITENS & ENUNCIADOS \\
\hline Conceitual & 08 & E5; E7; E11; E14; E19; E20; E21; E23 \\
\hline Procedimental & 06 & E2; E8; E12; E13; E22; E24 \\
\hline Formativo & 10 & E1; E3; E4; E6; E9; E10; E15; E16; E17; E18 \\
\hline Total & & $\mathbf{2 4}$ \\
\hline
\end{tabular}

Fonte: Autores (2019).

\section{Análises das médias e dos desvios padrões dos enunciados. $O$ modelo das crenças}

Uma vez selecionados os 24 enunciados que respondem aos critérios estabelecidos, procederam-se as análises das médias $(\bar{X})$ e desvios padrões (DP), com a finalidade de caracterizar as crenças e estabelecer um modelo que possa ser associado à maioria dos professores sobre o que são habilidades e sua formação no contexto do currículo escolar. Nos Quadros 3, 4 e 5, são apresentados os valores dessas medições.

O primeiro dos subdomínios para análise corresponde com a dimensão conceitual, que diz respeito ao que é uma habilidade. A dimensão conceitual pode ser reveladora de uma dimensão importante com a qual opera o pensamento dos professores em relação a suas crenças. 
Os valores das análises das médias e desvios padrões para os enunciados são apresentados no Quadro 3.

Quadro 3 - Média e desvio padrão para os enunciados do subdomínio conceitual

\begin{tabular}{|c|l|c|c|}
\hline Código & \multicolumn{1}{|c|}{ Enunciado SC } & $\overline{\boldsymbol{X}}$ & DP \\
\hline E5 & $\begin{array}{l}\text { Uma habilidade é uma formação psicológica executora } \\
\text { particular constituída por um sistema de operações do qual } \\
\text { se tem domínio para garantir as ações do sujeito sob } \\
\text { controle da consciência. }\end{array}$ & 2,63 & 0,94 \\
\hline E7 & $\begin{array}{l}\text { Como a teoria deve preceder a prática, as habilidades são } \\
\text { formas de se aplicar a teoria estudada. }\end{array}$ & 4,27 & 1,01 \\
\hline E11 & $\begin{array}{l}\text { A proposta de um currículo referenciado em habilidades } \\
\text { torna os objetivos educativos mais claros e precisos. }\end{array}$ & 3,97 & 0,92 \\
\hline E14 & $\begin{array}{l}\text { Uma habilidade é o resultado da sistematização de uma } \\
\text { competência geral. }\end{array}$ & $\begin{array}{l}\text { Acredito que uma habilidade expressa o domínio de um } \\
\text { sistema complexo de ações psíquicas e práticas necessárias } \\
\text { para a regulação racional da atividade. }\end{array}$ & 2,68 \\
\hline E20 & $\begin{array}{l}\text { Uma habilidade se situa no saber fazer. É necessário } \\
\text { primeiro se ter domínio do conceito para ser usado } \\
\text { posteriormente na formação de habilidades. }\end{array}$ & 3,86 & 1,01 \\
\hline E21 & $\begin{array}{l}\text { Pode-se ter domínio de um conceito desvinculado do } \\
\text { domínio de uma ou várias habilidades. }\end{array}$ & 3,68 & 1,03 \\
\hline E23 & $\begin{array}{l}\text { A formação de habilidades dificulta os processos criativos } \\
\text { na escola. }\end{array}$ & 1,88 & 1,04 \\
\hline
\end{tabular}

Fonte: Autores (2019).

O enunciado de maior média corresponde ao E7 ( $\bar{X}=4,27)$, com um desvio padrão de 1,01. Desse resultado depreende-se que, no geral, pode se considerar que os professores têm como elemento de suas crenças a exigência de a teoria preceder a prática, sendo a habilidade uma via para a aplicação e a aprendizagem dos conteúdos conceituais. De acordo com a teoria Histórico-Cultural, a habilidade (ação sistematizada) e o conceito constituem uma unidade (não uma identidade). Os conceitos se formam e desenvolvem em estreita união com as ações que, por sua vez, não existem fora dos conceitos (NÚÑEZ, 2009).

Esse elemento das crenças, exposto no enunciado E7, complementa-se e se integra aos valores correspondentes dos enunciados E20, $\operatorname{com} \bar{X}=3,86$ e DP $=1,05$, e E21, $\operatorname{com} \bar{X}=3,68$ e DP $=1,03$. Nesses, revelam-se, da mesma forma, a separação entre o conteúdo conceitual e o procedimental, ou seja, entre a aprendizagem de conceitos e a formação e o desenvolvimento 
das habilidades, o que, como explicam Núñez, Ramalho e Farias (2018), se torna incompatível com o marco teórico de referência deste trabalho.

O valor da média para o enunciado E20 permite confirmar que os professores, novamente, compartilham a ideia da separação entre o saber e o saber fazer, algo presente em documentos oficiais com a própria orientação teórica do Saeb, na qual se expressa:

O processo de construção do conhecimento passa, necessariamente, pelo saber fazer antes de ser possível compreender e explicar, até que este processo contínuo termine numa fase posterior de desenvolvimento com a tomada de consciência dos instrumentos utilizados e das relações estabelecidas (BRASIL. INEP, 2002, p. 11).

E continua:

As habilidades instrumentais referem-se especificamente ao plano do saber fazer e decorrem, diretamente, do nível estrutural das competências já adquiridas e que se transformam em habilidades (BRASIL. INEP, 2002, p. 1112).

Os enunciados com mais baixas médias referentes à dimensão conceitual de objeto das crenças são o E5, com $\bar{X}=2,63$ e DP $=0,94$, e o E19, $\operatorname{com} \bar{X}=2,68$ e DP $=0,91$. Esses valores indicam uma não concordância com o fato de as habilidades serem formações psicológicas da personalidade estruturadas em sistemas de operações das quais se têm domínio.

Cabe destacar que a característica de as habilidades serem ações das quais o sujeito tem domínio é referida por poucos professores. Baseados nos fundamentos de Leontiev (2001) e Petrovski (1985), os autores Rodriguez e Bermúdez (1999) entendem as habilidades como ações pertencentes aos sujeitos, os quais têm um pleno domínio sobre elas. A ação, uma vez dominada pelo sujeito através do processo de aprendizagem, transforma-se em habilidade. $\mathrm{Na}$ perspectiva desses autores, o grau de domínio é o critério para diferenciar ação de habilidade.

No entendimento de Núñez, Ramalho e Farias (2018), baseados do enfoque HistóricoCultural, as habilidades constituem elementos psicológicos estruturais da personalidade, vinculados à sua função reguladora-executora, que se formam, se desenvolvem e se expressam na atividade em estreita união com os elementos indutores da personalidade (motivos, valores, atitudes) e a comunicação. A habilidade é um tipo de atividade cognoscitiva, prática e valorativa que coloca o conhecimento teórico em ação.

É importante destacar uma alerta de Fariñas (2005) sobre as habilidades nesse marco teórico. Segundo a autora as habilidades têm sido tratadas como processos cognitivos, com 
certo consenso em relação a serem consideradas como um conjunto de ações que, fixadas (hábito) no processo de aprendizagem, fazem eficaz a execução humana. Na definição do conceito de habilidade, vinculam-se os componentes afetivos e cognitivos da personalidade, ou seja, as habilidades têm sempre um componente afetivo, valorativo. Conforme Fariñas (2005), as habilidades não podem ser consideradas só como uma sequência complexa de ações relacionadas com a eficácia da personalidade e seus processos, mas como unidades complexas, em cuja orientação intervêm valores, conceitos, ações, emoções, sentimentos, preferências e outros, que formam uma amálgama, para dar lugar a vivências encaminhadas ao alcance da eficácia.

Na consideração de Fariñas (2018), faz-se necessário compreender o sentido do conceito de habilidades no contexto do conceito de vivência desenvolvido por Vigotsky, em articulação com o de situação social de desenvolvimento, do mesmo autor.

Os enunciados E11, E14 e E21 apresentam médias que se correspondem com a concordância de um número importante de professores e um desvio padrão que caracteriza baixa dispersão em relação à média. O enunciado E11 se refere às habilidades como formas dos conteúdos que podem expressar os objetivos em termos das atividades necessárias para se aprender, o que é compatível com as ideias de Leontiev (1985) e Talízina (2000).

Segundo as implicações da Teoria de Atividade de Leontiev na escola, a aprendizagem se dá por um conjunto de atividades que o estudante realiza em situação social de comunicação, para se apropriar dos conteúdos escolares. Por isso, devem-se precisar as atividades (habilidades), que, em estreita união com os conteúdos conceituais e com os aspectos da personalidade a serem desenvolvidas nos estudantes, constituem objetivos de ensino e de aprendizagem.

O enunciado E14 (com $\bar{X}=3,67$ e DP $=1,01)$ mostra um acordo dos professores sobre as habilidades do currículo serem resultado da sistematização de uma competência geral. Embora na THC não se use o termo competência como dimensão dos conteúdos escolares, consideramos importante revelar essa relação para uma melhor compreensão do que vem a ser para os professores as habilidades do currículo escolar.

O conceito competência, no currículo escolar, constitui uma categoria imprecisa, que pouco tem contribuído na prática pedagógica de professores, embora a boa intencionalidade de sua inserção nos currículos como forma de fazer uma escola mais vinculada com a prática, com o cotidiano e com experiências das sociedades atuais. No entendimento de Fariñas (2010), embora o conceito de competência tenha conquistado ampla difusão no currículo escolar, ele 
representa um passo atrás na compreensão da aprendizagem e do desenvolvimento integral dos estudantes, no contexto escolar, sob a ótica da THC. Para a autora, a estrutura desse conceito aponta para a fragmentação do pensamento sobre a aprendizagem e o desenvolvimento humano e não para a visão complexa destes. No Quadro 4, são apresentados os valores das médias e dos desvios padrões para os enunciados do subdomínio procedimental das habilidades.

Quadro 4 - Média e desvio padrão para os enunciados do subdomínio procedimental

\begin{tabular}{|c|l|c|c|}
\hline Código & \multicolumn{1}{|c|}{ Enunciado SP } & $\overline{\boldsymbol{X}}$ & DP \\
\hline E2 & $\begin{array}{l}\text { Cada habilidade possui diversas estruturas de ações ou } \\
\text { "invariantes funcionais" que constituem diversidade na } \\
\text { sequência de passos a serem realizados na solução de um } \\
\text { grupo de tarefas do mesmo tipo. }\end{array}$ & 2,52 & 1,09 \\
\hline E8 & $\begin{array}{l}\text { Sou da opinião de que cada habilidade possui uma estrutura } \\
\text { de ações ou “invariante funcional" que constitui a sequência } \\
\text { de passos a serem realizados na solução de um grupo de } \\
\text { tarefas do mesmo tipo. }\end{array}$ & 2,68 & 1,02 \\
\hline E12 & $\begin{array}{l}\text { Penso que uma habilidade pode ser considerada como a } \\
\text { capacidade de se pôr o conhecimento em ação. }\end{array}$ & $\begin{array}{l}\text { As habilidades e as competências apresentam a mesma } \\
\text { natureza, diferenciando-se só no fato de serem as habilidades } \\
\text { tipos de competências de menor abrangência. }\end{array}$ & 4,82 \\
\hline E22 & $\begin{array}{l}\text { Uma habilidade como conhecimento procedimental é de } \\
\text { natureza mecanicista, consequentemente não precisa da } \\
\text { atividade consciente. }\end{array}$ & 2,31 & 1,04 \\
\hline
\end{tabular}

Fonte: Autores (2019).

Constata-se que os valores das médias dos enunciados E2 e E8 correspondem a um baixo nível de acordo, ou seja, os professores não concordam com duas ideias apresentadas nos enunciados de forma contraposta. Isso deixa em aberto esse elemento que caracteriza a estrutura operacional das habilidades no referencial adotado.

Uma habilidade se caracteriza por um sistema de operações (uma invariante operacional) que interage com um sistema de conhecimentos, assim como com atitudes e valores, na solução de tarefas que podem ser resolvidas por essa via.

A ação apresenta um aspecto operacional (como e por quais meios se podem atingir os objetivos) definido pelas condições objetivas necessárias para se atingir o objetivo da atividade, junto ao aspecto intencional (aonde se quer chegar) determinado não pelas metas, e sim pelas condições objetivas para se alcançar a meta. Para Leontiev (2001), a ação tem uma forma de ser executada, que é denominada de operação; enquanto a ação diz respeito às metas, as 
operações estão relacionadas às condições. Dessa forma, a atividade não é só uma ação ou uma série de ações apropriadas, mas um sistema com estrutura, desenvolvimento, transições e mudanças internas.

Em relação ao enunciado E12, os professores concordam, em grande medida, em considerar as habilidades como capacidades para se pôr conhecimentos em ação, o que é manifesto nos valores de $\bar{X}=4,82$ e DP $=0,89$. No marco da teoria Histórico-Cultural, os autores têm posturas diferentes ao diferenciar capacidades de habilidades, como alerta Fariñas (2005). O conceito de capacidade, na THC, tem sido amplamente discutido por autores como Vigotsky (1989), Leontiev (1985), Petrovski (1985), Talízina (2000), Davidov (1988), Rodriguez e Bermúdez (1999), Fariñas (2010), entre outros. Nessas discussões, constatam-se pontos divergentes e convergentes.

Pautada no conceito de vivência de Vigotsky, Fariñas (2010, p. 94) assinala:

A capacidade, como construção teórica refere-se ao entramado vivencial, que permite uma eficácia generalizada. A capacidade é o resultado da integração e ao mesmo tempo generalização das habilidades. Em outras palavras, é uma formação psicológica complexa continente da trama de habilidade.

Um outro enunciado para o qual se observa uma concordância dos professores é o E13, $\operatorname{com} \bar{X}=4,21$ e DP=1,04. Esse resultado leva a pensar que eles compartilham a ideia de que as habilidades e as competências têm a mesma natureza, diferenciando-se só no grau de abrangência, o que é coerente com as ideias que fundamentam a matriz de avaliação do ENEM (MACEDO, 2005).

Outro enunciado que entra na configuração do subdomínio procedimental das crenças em estudo é o E22, para o qual $\bar{X}=2,31$ e o $\mathrm{DP}=1,08$. Esses valores apontam para uma não concordância com a ideia de que as habilidades sejam procedimentos de natureza mecanicista, que não exigiria uma atividade consciente do sujeito, ideia esta incompatível com os pressupostos da THC.

Os valores das médias e dos desvios padrões para a dimensão da formação de habilidades se apresenta no Quadro 5. Essa dimensão é significativa, uma vez que se relaciona não só com o que é uma habilidade e sua estrutura, mas também com os processos de sua formação no contexto escolar, aspecto relevante no desenvolvimento do currículo. 
Quadro 5 - Médias e desvios padrão dos enunciados para o subdomínio formativo

\begin{tabular}{|c|c|c|c|}
\hline Código & Enunciado SF & $\bar{X}$ & DP \\
\hline E1 & $\begin{array}{l}\text { Acredito que as habilidades se formam como atividades } \\
\text { reprodutivas (repetição do conteúdo de forma mecânica). }\end{array}$ & 3,57 & 1,13 \\
\hline E3 & $\begin{array}{l}\text { Sou da opinião de que a formação de habilidades exige do } \\
\text { professor um planejamento coerente com o princípio de } \\
\text { sistematização dos conteúdos. }\end{array}$ & 3,27 & 0,80 \\
\hline $\mathrm{E} 4$ & $\begin{array}{l}\text { Penso que a formação de uma habilidade é um processo de } \\
\text { apropriação consciente de modos de agir. }\end{array}$ & 2,02 & 0,88 \\
\hline E6 & $\begin{array}{l}\text { No processo de formação das habilidades, é conveniente que } \\
\text { o aluno descubra por si só a estrutura de ações ou sequência } \\
\text { de passos que deve realizar, o que torna a aprendizagem mais } \\
\text { interessante. }\end{array}$ & 3,90 & 1,26 \\
\hline E9 & $\begin{array}{l}\text { As habilidades se formam como atividades produtivas } \\
\text { (repetição e aplicação do conteúdo de forma consciente). }\end{array}$ & 2,00 & 0,84 \\
\hline E10 & $\begin{array}{l}\text { Acredito que a formação de uma habilidade é um processo } \\
\text { do tipo "tudo ou nada", pelo que não tem sentido se falar de } \\
\text { graus de desenvolvimento da mesma. }\end{array}$ & 1,86 & 0,92 \\
\hline E15 & $\begin{array}{l}\text { As habilidades se formam e desenvolvem pela via da } \\
\text { sistematização, do treinamento contínuo da estrutura de } \\
\text { ações que a formam. }\end{array}$ & 2,63 & 0,92 \\
\hline E16 & $\begin{array}{l}\text { Sou da opinião de que uma habilidade se forma no nível de } \\
\text { fixação dos conhecimentos, por isso se situa no campo da } \\
\text { aprendizagem memorística. }\end{array}$ & 2,43 & 1,01 \\
\hline E17 & $\begin{array}{l}\text { Uma habilidade se forma no nível de aplicação dos } \\
\text { conhecimentos, por isso se situa no campo da aprendizagem } \\
\text { produtiva. }\end{array}$ & 2,81 & 0,87 \\
\hline E18 & $\begin{array}{l}\text { Uma habilidade pode se desenvolver quando, uma vez } \\
\text { apropriado os modos da ação, exercita-se a habilidade com } \\
\text { uma frequência adequada, de modo a se eliminar os erros na } \\
\text { solução das tarefas. }\end{array}$ & 3,63 & 1,12 \\
\hline E24 & $\begin{array}{l}\text { A formação de uma habilidade exige a sistematização não } \\
\text { consciente da sua estrutura operacional (sistema de ações } \\
\text { que a compõe). }\end{array}$ & 4,02 & 1,09 \\
\hline
\end{tabular}

Fonte: Dados da pesquisa (2019).

O enunciado que apresenta maior grau de concordância neste subdomínio é o E24, para o qual $\bar{X}=4,02$ e DP $=1,09$. Esse resultado não é coerente com os postulados da THC e se contradiz com a não concordância com o enunciado $\mathrm{E} 4, \bar{X}=2,02$ e DP $=0,88$, ao considerar a formação da habilidade como um processo consciente.

A formação de uma habilidade é um processo que implica apropriação consciente dos modos de fazer, em estreita união com os conceitos necessários para a ação quando, sob a orientação do professor, o aluno passa a ter consciência do sistema de ações e operações da habilidade como forma de atividade e, com base nesse modelo, resolve diferentes tarefas com 
sucesso. Por sua vez, o desenvolvimento da habilidade se refere ao processo de aplicação e consolidação da habilidade formada, na solução de tarefas de naturezas produtivas e criativas.

Os professores apresentam discordância com os enunciados $\mathrm{E} 9(\bar{X}=2,00 \mathrm{DP}=0,80)$, $\mathrm{E} 10(\bar{X}=1,86, \mathrm{DP}=0,92), \mathrm{E} 15(\bar{X}=2,63 ; \mathrm{DP}=0,92)$ e E16 $(\bar{X}=2,43$ e DP $=0,87)$. Nesses casos, os professores pouco consideram o papel da consciência na atividade do sujeito, sendo a formação da habilidade um processo que não se produz por etapas, podendo ser caracterizada por níveis de desenvolvimento.

A formação da habilidade é um processo que vai passando por níveis diferentes, cada vez mais complexos e aprofundados, que devem levar os estudantes a ampliarem suas possibilidades de uso dos conhecimentos e das habilidades de forma criativa, como parte do pensamento estratégico, assim como se tornarem um elemento de sua personalidade.

Existe certa concordância dos professores com a ideia de que a formação das habilidades seja uma aprendizagem memorística $(E 16, \bar{X}=2,43$ e DP $=1,01)$ e com a de que seja uma repetição dos conteúdos de forma mecânica (enunciado E1, com $\bar{X}=3,57$ e DP $=1,13$ ). Esses resultados são contrários ao entendimento da THC sobre a formação de habilidades, na qual a compreensão tem um papel essencial, relacionado com a consciência que se tem desse processo.

Os valores numéricos do enunciado E18, para o qual $\bar{X}=3,63$ e DP $=1,12$, expressam certa concordância com o processo de desenvolvimento da habilidade, com um processo de sistematização desta, o que é compatível com as posturas teóricas de autores do enfoque Histórico-Cultural. Existe certo consenso, nesse enfoque, de se diferenciar a formação do desenvolvimento da habilidade.

A formação de uma habilidade é um processo complexo que implica a apropriação consciente dos modos de atuação, em estreita união com os conceitos necessários para a ação. Quando sob a orientação do professor, o estudante passa a ter consciência do sistema de ações e operações da habilidade e, como explicam Núñez, Ramalho e Farias (2018), possibilita resolver com eficiência determinadas tarefas ou situações-problema.

Por sua vez, o desenvolvimento da habilidade se refere ao aperfeiçoamento da habilidade formada. Uma habilidade nunca existe de forma isolada, mas relacionada a outras num sistema complexo e, dessa forma, ela se aperfeiçoa na medida que outras habilidades se formam e se aperfeiçoam.

Existe, por outro lado, uma baixa concordância e discordância em relação ao enunciado E3, $\bar{X}=3,27$ e DP $=0,80$. No geral, os professores podem não concordar com a importância do planejamento da formação de habilidades em coerência com o princípio de sistematização 
dos conteúdos. Na THC, a influência da aprendizagem no desenvolvimento do estudante é um processo pedagogicamente intencional, o qual exige do professor um planejamento consciente. Segundo Núnez, Ramalho e Farias (2018), a formação de habilidades como atividade consciente é um processo dinâmico que necessita de planejamento e fundamentação teórica por parte dos professores para a tomada de decisões didáticas coerentes com determinados pressupostos do ensino e da aprendizagem no contexto escolar.

Os valores atribuídos ao enunciado E6 $(\bar{X}=3,90$ e DP $=1,26)$ evidenciam um nível aceitável de concordância com a ideia de os estudantes descobrirem por si só a estrutura da ação ou sistema de operações da ação correspondente à habilidade a ser formada. Na THC, não se expressa essa postura teórica, que caracteriza uma "aprendizagem por descoberta".

Como resultado da formação e do desenvolvimento de habilidades, deve acontecer a formação de novas qualidades da personalidade e do intelecto dos estudantes, que dizem respeito ao seu desenvolvimento integral como consequência das interações dialéticas da aprendizagem com o desenvolvimento. A aprendizagem está associada ao desenvolvimento integral do estudante e à sua subjetividade como membro de um grupo social. Embora as habilidades funcionem em atividades de natureza produtiva (e não reprodutiva), elas são essenciais para o pensamento estratégico, para a tomada de decisões e para a atividade criativa.

Sob o enfoque teórico que se assume, não é objetivo do ensino que os estudantes façam a descoberta por si mesmos da estrutura do sistema de operações de uma dada ação/habilidade, o que, como explica Talízina (2000), seria um ato criativo de muita dificuldade para os estudantes. Assim, parte-se do conhecimento que possam ter os estudantes sobre a estrutura de operações da ação e, no contexto das necessidades de solução de uma situação-problema na qual se faz necessária a ação, sob a mediação pedagógica do professor, criam-se condições para os estudantes reelaborarem a representação que têm da ação. Essa reelaboração consiste num processo de negociação entre sentidos atribuídos por eles a esse objeto do conhecimento e o significado estabelecido na disciplina, no contexto do grupo.

Após as análises dos enunciados, foi realizada a definição do modelo das crenças dos professores sobre as habilidades e sua formação no contexto escolar por meio da seleção e integração dos conteúdos dos enunciados de maiores médias (maior de $\bar{X}=4$ ) e menores desvios padrão, assim como os de menores média (menor de $\bar{X}=2$ ) e menores desvio padrão. Dessa forma, com a triangulação dos conteúdos desses enunciados, realizou-se uma inferência do modelo de crenças dos professores sobre as habilidades e sua formação no contexto escolar, a qual se mostra no Quadro 6. 
Quadro 6 - Modelo de crenças sobre as habilidades e sua formação no contexto escolar

\begin{tabular}{|c|c|}
\hline $\begin{array}{c}\text { Enunciados de maiores média e } \\
\text { menores desvio padrão. }\end{array}$ & $\begin{array}{c}\text { Modelo de crenças. } \\
\text { E7, E12, E13, E24. }\end{array}$ \\
$\begin{array}{c}\text { As habilidades são formas de se aplicar a } \\
\text { teoria estudada, são capacidades que } \\
\text { permitem pôr o conhecimento em ação, } \\
\text { apresentando a mesma natureza das } \\
\text { competências, sendo de menor abrangência } \\
\text { que essas. Sua formação exige a } \\
\text { sistematização não consciente da sua } \\
\text { desvio padrão. } \\
\text { E23, E10. }\end{array}$ & $\begin{array}{c}\text { acontece segundo diferentes graus de } \\
\text { desenvolvimento. }\end{array}$ \\
\hline
\end{tabular}

Fonte: Autores (2019).

É importante entender a importância da dialética entre o geral, atribuído na pesquisa ao modelo das crenças dos professores como grupo, e o singular, caracterizado nas respostas de cada professor, para os quais os processos formativos devem prestar atenção quando se propõem estimular os professores a refletir de forma crítica sobre suas crenças em relação a domínios da atividade profissional.

\section{Conclusões}

O estudo, de natureza exploratória, possibilitou uma aproximação às crenças de professores da educação básica sobre as habilidades e sua formação no contexto escolar, sob a ótica da THC. Em detrimento da não existência de unanimidade em relação a algumas categorias teóricas dentro da própria THC, procurou-se um consenso com base no qual se estruturou o marco teórico da pesquisa. Para o levantamento dos dados, o questionário construído se mostrou adequado em relação a sua validez e sua consistência interna, considerando os objetivos e a natureza do estudo.

As análises das médias e dos desvios padrões permitiram evidenciar que, segundo o modelo estabelecido, as habilidades se referem, fundamentalmente, ao saber fazer, o que está muito presente em diversas perspectivas e discussões teóricas, como as de Macedo (2003). Além disso, as habilidades têm a mesma natureza que as competências, sendo a diferença fundamental relacionada ao nível de abrangência, aspecto presente em documentos oficiais como o das Orientações Teórico-Metodológicas do ENEM. Por sua vez, um grupo significativo de professores evidencia um afastamento de suas crenças sobre algo relevante no marco da 
THC, como é o nível consciente da realização da habilidade. Por último, inclui-se no modelo de crenças que a formação das habilidades é um processo que se dá em diferentes graus de desenvolvimento.

É importante ressaltar que esses aspectos levantados podem ter influência na prática pedagógica das atividades para a formação e o desenvolvimento das habilidades definidas no currículo escolar, e necessárias para as aprendizagens dos estudantes. As relações entre crenças dos professores e sua prática profissional são interpretadas sob diferentes pontos de vista (WOODS, 1996).

Richardson (1996) afirma que é reconhecido o fato de não só as crenças influenciarem sobre a ação, como também a experiência influenciar na formação e na mudança de crenças. Segundo essa autora, estudos realizados dentro de uma perspectiva hermenêutica, que procuram compreender as complexidades dos processos de pensamento e das ações em relação aos contextos de ensino, têm demonstrado a existência do desencontro entre crenças e ações (as crenças não correspondem necessariamente à ação). Nesse sentido, as práticas de professores podem revelar contradições com as crenças. Assim, a crença pode evoluir, mas o comportamento não acompanha a evolução da crença, encontrando-se fossilizado em estado pré-crença.

Não obstante, os resultados permitem aproximações das crenças de professores sobre as categorias relevantes para a prática profissional considerando que se trata de um componente do pensamento docente que serve de marco de referência para os professores darem sentido a suas práticas como profissionais.

Pode-se, assim, concluir que o modelo das crenças dos professores se mostra contraditória com as ideias da THC. Sendo assim, a formação continuada se institui em um espaço privilegiado de reflexão crítica sobre essas crenças, como elemento do desenvolvimento profissional que se deve traduzir em melhores práticas de ensino para uma aprendizagem que tribute ao desenvolvimento integral dos estudantes.

Uma vez que neste trabalho se interpretam as crenças sob a perspectiva da THC, em certa medida, mostra-se limitado a esse quadro de referência, não sendo possível inferir crenças sob outras perspectivas teóricas. Por sua vez, o questionário elaborado, embora apresente validade e consistência interna para os fins da pesquisa, pode ser aperfeiçoado sob outros critérios de confiabilidade, o que abre caminho para novos estudos. 


\section{REFERÊNCIAS}

ASHTON, Patricia. Historical Overview and Theoretical Perspectives of Research on Teachers' Beliefs. In: FIVES, Helenrose; GILL, Michele Gregoire. International Handbook of Research on Teachers' Beliefs. Abingdon: Routledge, 2014. Disponível em: < https://www.routledgehandbooks.com/doi/10.4324/9780203108437.ch3 >. Acesso em: 13 abr. 2019. p. 30-53.

BARAHONA, Malba. Pre- service teachers' beliefs in the activity of learning to teach English in the Chilean context. Cultural - Historical Psychology, Moscow, v. 10, n. 2, p. 116-122, 2014.

BARDIN, Laurence. Análise de Conteúdo. Lisboa: Edições 70, 2011.

BRASIL. Instituto Nacional de Estudos e Pesquisas Educacionais Anísio Teixeira (INEP). Saeb 2001: novas perspectivas. Brasília: INEP, 2002.

CLARK, Christopher; PERTESON, Penélope. Procesos del pensamiento de los docentes. In: WITTROCH, Merlin (org.). La investigación docente de la enseñanza II: profesores y alumnos. Barcelona: Ediciones Paidós Ibérica. S. A., 1997. p. 444-543.

CRONBACH, Lee. Coefficient alpha and internal structure of tests. Psychometrika, Berlim, v. 16, n. 3, p. 297-334, 1951.

DANILOV, Mikhail; SKATKIN, Mikhail. Didáctica de la escuela media. La Habana: Editorial de Libros para la Educación, 1980.

DAVIDOV, Vasily Vasilyevich. EI contenido y la estructura de la actividad docente de los escolares. La Habana: Editorial Pueblo y Educación, 1988.

DAVIDOV, Vasily Vasilyevich; SLOBODCHIKOV, Viktor Ivanovich. La enseñanza que desarrolla en la escuela del desarrollo. In: MUDRIK, Anatoliy Viktorovich. La educación y la enseñanza: una mirada al futuro. Moscú: Progreso, 1991. p. 118-145

ENGESTROM, Yrjö. Learning at work: toward an activity theoretical reconceptualization. Journal of Education and Work, Bath, v. 14, n. 1, p. 133-156, 2001.

FARIÑAS, Gloria León. Psicología, Educación y Sociedad. La Habana: Editorial Felix Varela, 2005.

FARIÑAS, Gloria León. A interdisciplinaridade nas Ciências Sociais: a contribuição da Psicologia desde o pensamento complexo. São Paulo: Terceira Margem, 2010.

FARIÑAS, Gloria León. Para ler Galperin. In: NÚÑEZ, Isauro Beltrán; RAMALHO, Betânia Leite (orgs). Galperin e a Teoria de Formação Planejada por Etapas das Ações Mentais e dos Conceitos: Pesquisas e experiências para um ensino inovador. Campinas: Mercado de Letras, 2018. p. 79-100. 
GALPERIN, Piotr. Acerca del lenguaje interno. In: ROJAS, Luis Quintanar (Comp.). La formación de las funciones psicológica durante el desarrollo de niño. Tlaxcala: Editora Universidad Autónoma de Tlaxcala, 2001. p. 57-66.

LEONTIEV, Aleksei. Actividad, consciencia y personalidad. La Habana: Pueblo y Educación, 1985.

LEONTIEV, Aleksei. Acerca de la importancia del concepto de actividad objetal para la psicología. In: ROJAS, Luis Quintanar. (Comp). La formación de las funciones psicológica durante el desarrollo del niño. Tlaxcala: Editora Universidad Autónoma de Tlaxcala, 2001. p. $15-26$.

LINARES, Salvador Ciscar. La formación de profesores de matemáticas. Sevilla: Universidad de Sevilla, 1991.

MACEDO, Lino de. Para o desenvolvimento de competências e habilidades na escola. In: MATOS, C. (org.). Ciência e arte: imaginário e descoberta. São Paulo: Estação Ciência, USP, 2003. p. 41-49.

MACEDO, Lino de. Competências e habilidades: Elementos para uma reflexão pedagógica. In: MORAIS, Jair Santana. Exame Nacional do Ensino Médio (ENEM): Fundamentação teórico-metodológica. Brasília: O Instituto (INEP/MEC), 2005.

MARCELO, Carlos Garcia. Formalidade e informalidade no processo de aprender a ensinar. In: VALDÉS, Roberto Puentes; AQUINO, Orlando Fernández; LONGAREZI, Andrea Maturano. (orgs.). Ensino Médio: estado atual, políticas e formação de professores. Uberlândia: EDUFU, 2012. p. 181-204.

MARCELO, Carlos Garcia; VAILLANT, Denise. Desarrollo profesional docente. ¿Cómo se aprende a enseñar? Madrid: Narcea S. A. Ediciones, 2009.

NEGUERUELA, Eduardo. Beliefs as conceptualizing activity: A dialectical approach for the second language classroom. System, Amsterdã, v. 39, n. 3, p. 359-369, 2011.

NOCEDO, Irma León. Metodología de la Investigación Educacional. $2^{\text {a }}$ parte. La Habana: Editorial Pueblo y Educación, 2001.

NUÑEZ, Isauro Beltrán. Vygotsky, Leontiev, Galperin. Formação de conceitos e princípios didáticos. Brasília: Líber Livro, 2009.

NUÑEZ, Isauro Beltrán. O diagnóstico dos níveis de orientação da ação classificar: contribuições da teoria de P. Ya. Galperin. In: FEITOSA, Raphael Alves; SILVA, Salonildo Almeida. Metodologias emergentes na pesquisa em ensino de ciências. Porto Alegre: Editora Fi, 2018. p. 157-175.

NÚÑEZ, Isauro Beltrán; RAMALHO, Betânia Leite. Desarrollo de una Unidad Didáctica para el estudio de los procesos de oxidación-reducción en el pre-universitario: contribuciones de la teoría de P. Ya. Galperin. In: SILVA, Marcia Gorette Lima da; MOHR, Adriana; FERNÁNDES, Magnolia Florência de Araújo. Temas de Ensino e Formação de Professores de Ciências. Natal: EDUFRN, 2012. p. 153-180. 
NÚÑEZ, Isauro Beltrán; RAMALHO, Betânia Leite; FARIAS, Marcus Vinicius Oliveira. A formação de habilidades gerais no contexto escolar: contribuições da teoria de P. Ya. Galperin. In: NÚÑEZ. Isauro Beltrán; RAMALHO, Betânia Leite (orgs). Galperin e a Teoria de Formação Planejada por Etapas das Ações Mentais e dos Conceitos. Pesquisas e experiências para um ensino inovador. Campinas: Mercado de Letras, 2018. p. 23-78.

PAJARES, Frank. Teacher's beliefs and educational research: Cleaning up a Messy Construct. Review of Educational Research, University Park, v. 62, n. 3, 1992.

PÉREZ, Angel Ignacio Gómez. Compreender o ensino na escola: modelos metodológicos de investigação educativa. In: SACRISTÁN, José Gimeno; PÉREZ, Angel Ignácio Gómez. Compreender e transformar o ensino. 4. ed. Porto Alegre: Artmed, 2007. p. 99-118.

PETROVSKI, Arthur Vladimirovich. Psicologia Evolutiva y pedagógica. Moscú: Editorial Progreso, 1979.

PETROVSKI, Arthur Vladimirovich. Dicionário psicológico breve. Moscú: Politis, 1985.

PORLÁN, Rafael Ariza; DEL POZO, Rosa Maria; TOSCANO, Martin. Conceptions of School - Bases teacher educations concerning on going teacher education. Teching and Teacher Education, Amsterdã, n. 18, p. 305-321, 2002.

PORLÁN, Rafael Ariza; RIVERO, Ana Garcia. El conocimiento de los profesores. Madrid: Diada Editorial, 1997.

POZO, Juan Ignácio. La nueva cultura del aprendizaje en la sociedad del conocimiento. In: POZO, Juan. Ignácio (orgs.). Nuevas formas de pensar la enseñanza y el aprendizaje. Barcelona: Grao, 2006. p. 29-54.

POZO, Juan Ignácio; GÓMEZ CRESPO, Miguel Angel. A aprendizagem e o ensino de ciências. Do conhecimento cotidiano ao conhecimento cientifico. $5^{\mathrm{a}}$ ed. Porto Alegre: ArtMed, 2009.

RAMALHO, Betânia Leite; NUÑEZ, Isauro Beltrán; GAUTHIER, Clemont. Formar o professor, profissionalizar o ensino: perspectivas e desafios. 2. ed. Porto Alegre: Sulina, 2004.

RICHARDSON, Virginia. The role of attitudes and beliefs in learning to teach. In: SIKULA, John. (org.). Handbook of Research on Teacher Education. $2^{\text {a }}$ ed. New York: Macmillan, 1996. p.102-119.

RODRIGO, Maria José; RODRÍGUEZ, Armando Pérez; MARRERO, Javier. Las Teorías Implícitas: una aproximación al conocimiento cotidiano. Madrid: Visor Editora, 1993.

RODRIGUEZ Marisela Robustillo; BERMÚDEZ, Rogério Sarguera. Psicología del pensamiento científico. La Habana: Editorial Pueblo y Educación, 1999.

TALÍZINA, Nina Fidorova. Manual de Psicología Pedagógica. Editora de la Facultad de Psicología. San Luis Potosí, S.L.P., 2000 
TALÍZINA, Nina Fidorova. La formación de las habilidades del pensamiento matemático. San Luis Potosí: Editora Universidad de San Luis Potosí, S.L.P., 2001.

TALÍZINA, Nina Fidorova. Mecanismos psicológicos de la generalización. Acta

Neurológica Colombiana, Bogotá, v. 24, n. 2, junio. Suplemento (2-1), p. 76-87, 2009.

TARDIF, Maurice. Saberes docentes e prática profissional. Petrópolis: Vozes, 2002.

VIGOTSKY, Lev Semionovitch. EI desarrollo de los procesos psicológicos superiores. Ciudad de México: Grijalbo, 1988.

VIGOTSKY, Lev Semionovitch. Pensamiento y lenguaje. La Habana: Pueblo y Educación, 1989.

WOODS, Devon. Teacher cognition in language teaching: Beliefs, decision - making and classroom practice. Cambridge: Cambridge University Press, 1996.

ZABALA, Antoni; ARNAU, Laia. Como aprender e ensinar competências. Tradução de Carlos Henrique Lucas Lima. Porto Alegre: Artmed, 2010

ZABALZA, Miguel Angel. Diários de aula: contributos para o estudo dos dilemas práticos dos professores. Porto: Porto Editora, 1994.

Agradecimento: Agradecimento pelo apoio que foi recebido pelo CNPQ e da Comperve/UFRN.

\section{SOBRE OS AUTORES:}

\section{Isauro Beltrán Núñez}

Doutor em Ciências Pedagógicas pela Universidade de Havana, Havana, Cuba. Departamento de Práticas Educacionais e Currículo - Universidade Federal do Rio Grande do Norte (UFRN). Bolsista de Produtividade em Pesquisa do CNPq. Grupo de Pesquisa: Aprendizagem Formação e profissionalização Docente. E-mail: isaurobeltran@yahoo.com.br

(iD) http://orcid.org/0000-0003-3224-4694

\section{Magda Maria Pinheiro de Melo}

Mestre em Engenharia Sanitária pela Universidade Federal do Rio Grande do Norte. Natal, Brasil. Departamento de Engenharia Civil - Universidade Federal do Rio Grande do Norte. Grupo de Pesquisa: Aprendizagem Formação e profissionalização Docente. E-mail: magdampm@hotmail.com

(iD http://orcid.org/0000-0001-8241-0967

Recebido em: 29 de maio de 2019 Aprovado em: 14 de fevereiro de 2020

Publicado em 01 de abril de 2020 